\title{
Uma nova Trigonia da flora da Venezuela
}

\author{
Eduardo Lleras (")
}

\section{Resumo}

Apresenta-se uma nova Trigoniacea, Trigonia ehrendorferii, da Flora de Venezuela.

\section{INTRODUÇÃo}

Este trabalho é mais uma contribuição ao conhecimento das Trigoniáceas. É assim uma continuação da Monografia da Família (Lleras, 1978), na qual lamentavelmente năo foi possível incluir esta espécie.

Trigonia ehrendorferii Lleras, sp. nov. (Fig. 1)

Frutex scandens (?), ramulis juvenilibus dense lanatis. Stipulae caducae, connatae, ca $7 \mathrm{~mm}$ longae, $2,5 \mathrm{~mm}$ latae, chartaceae, lanatae. Folia oposita, petiolo $5,5-11 \mathrm{~mm}$ longo, $1-1,5 \mathrm{~mm}$ crasso, lanato; laminae subrotundae, $3.8 \mathrm{~cm}$ longae, $2.5 .6 \mathrm{~cm}$ latae, chartaceae, margine integrae, apice mucronulato usque emarginato varianti, basi obtusa, supra leviter lanatae, infra adpresso-lanatae; costa media supra plana, dense lanata, infra prominula, lanata, costis secundariis 6-9 jugis. Inflorescentiae in paniculis terminalibus vel axillaribus dispositae, $5-12 \mathrm{~cm}$ longae. Flores in cincinnos 1-bifloris: ad extremum in inflorescentias secundarias dispositi, ab dichasiis dichotomis usque cincinnos solitarios variantes; axibus inflorescentiarum secundariarum 0,8-1,5 (-2) $\mathrm{mm}$ longi, $0,7-0,9 \mathrm{~mm}$ crassis, strigosis; pendunculi $0,8-1,5 \mathrm{~mm}$ longi, $0,8-0,9$ $\mathrm{mm}$ crassi, tomentelli, bracteis subulatis, 3.4.5 mm longis, margine glanduloso-papillatis, tomentellis; pedicelli $2-2,5 \mathrm{~mm}$ longi, $0,4-0,5 \mathrm{~mm}$ crassi, tomentelli, bracteolis subulatis, 1,5-3 $\mathrm{mm}$ longis, margine ut in bracteis, tomentellis; sepala ovata vel oblonga, $2,2-4,5 \mathrm{~mm}$ longa, $0,8-1,5 \mathrm{~mm}$ lata, nonnumquam glandulosa, tomentella; vexillum $3,8-4,2 \mathrm{~mm}$ longum, 1-1,4mm latum, usque ad medium longitudinaliter saccatum, apice leviter revolute, intus barbatum, alae spathulatae, $2,5-3,1 \mathrm{~mm}$ longae, $0,6-0,8 \mathrm{~mm}$ latae, ad basin barbatae, carinae petala sacata. 2,1-2,5 mm Ionga, 1-1,3 mm lata, glabra; stamina $8-9$, sterilia 2 , fertilia $6-7$, staminodiis nonnumquam appendiculatis, filamentis ad medium connatis, 2-2.4 $\mathrm{mm}$ longis, antheris oblongis vel obovatis, $0,4-0,5 \mathrm{~mm}$ longis, $0,2-0,3$ $\mathrm{mm}$ latis: glandulae 2,1-2 lobae, laciniate, nonnumquam appendiculatae, ca $0,8 \mathrm{~mm}$ longae, $0,6 \mathrm{~m}$ latae, lanatae; stylus erectus, 1-1,2 $\mathrm{mm}$ longus, glaber, stigmate circulari, albo ca $0,3 \mathrm{~mm}$ lato; ovarium pyramidale, ca $0,8 \mathrm{~mm}$ latum 3-loculare, dense villosum, ovulis in quoque loculo numerosis. Fructus mihi ignotus.

Esta espécie comparte a presença de glândulas nas sepalas, brácteas e bracteolas com Trigonia bracteata e Trigonia reticulata (Lleras, 1978), as duas também da Venezuela. Difere delas, porém, em outros caracteres tanto vegetativos quanto reprodutivos. A falta de fruto faz, como no caso de outras espécies de Trigonia, impossivel a determinação de afinidades. Esta espécie é dedicada ao seu coletor, o Dr. F. Ehrendorfer.

TIPO: F. Ehrendorfer 74109-15, Venezuela, Bolívar, Gran Sabana, Canaima, 9 Out. $1974 \mathrm{fl}$. (Holótipo VEN).

HABITAT: Margem de savana e floresta. Arenisco Precambriano, alt. 500-600 m.

DISTRIBUIÇÃo: Só conhecida da localidade típica.

\section{SUMMARY}

A new species of Trigoniaceae from Venezuela, Trigonia ehrendorferii is here presented.

\section{BIBLIOGRAFIA CITADA}

LLERAS, E.

1978 - A Monograph of the Family Trigoniaceae. Flora Neotropica Monograph, 19. $79 \mathrm{p}$.

(Aceito para publicação em 07-06-78)

(*) - Instituto Nacional de Pesquisas da Amazônia, Manaus. 


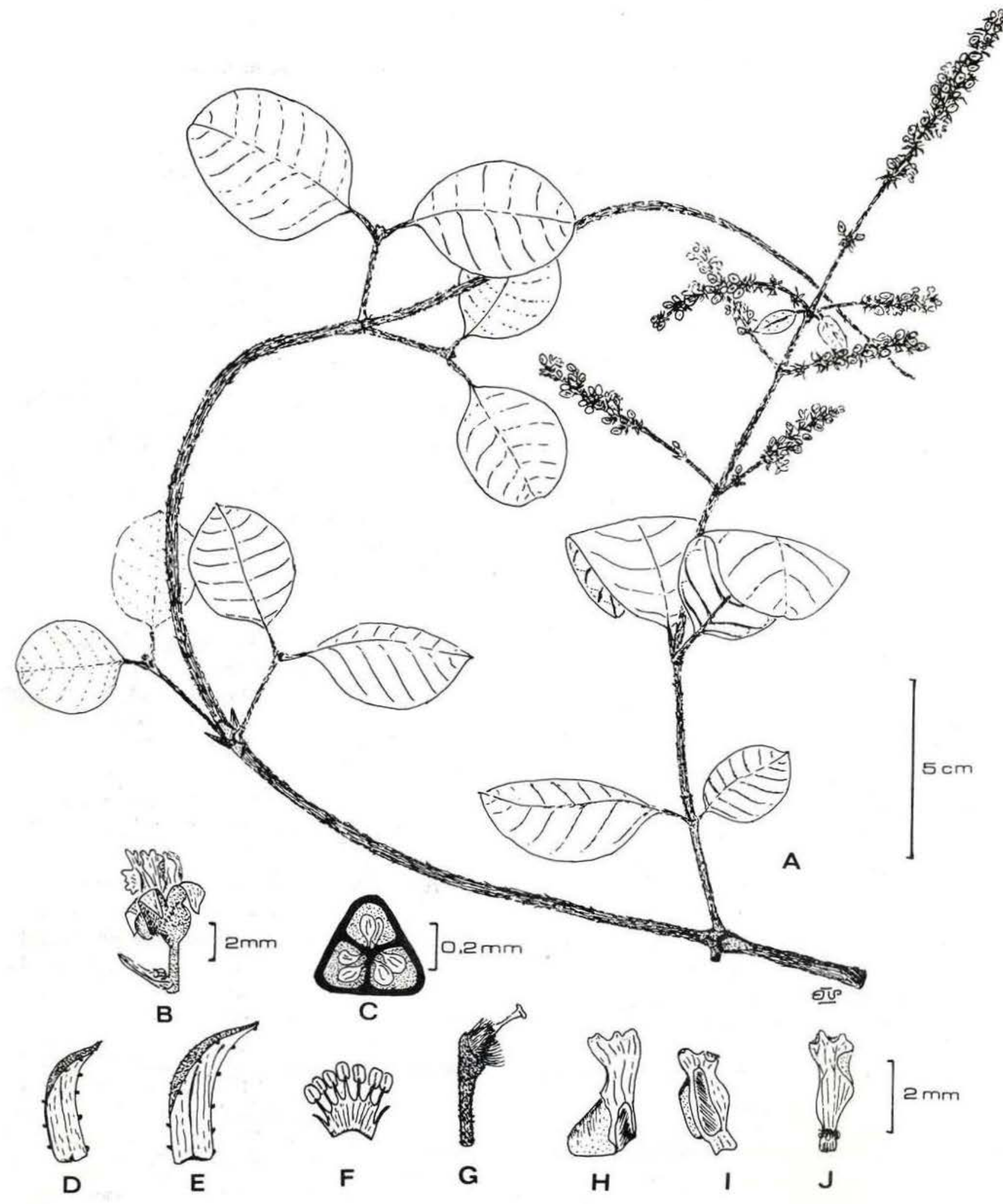

Fig. 1 - Trigonia ehrendorferii. A, Hábito; B, Secçăo transversal do ovário; D, Bracteola; F, Bractea; F, Estames; G, Gineceu; H, Estandarte; I, Pétala da quilha; J, Asa. 